\title{
Um modelo aplicado à melhoria dos processos de planejamento estratégico e autoavaliação em Instituições de Ensino Superior Privadas
}

\author{
Josias Ezequiel Julierme Mazzurana ${ }^{1}$ \\ Carlos Fernando Jung ${ }^{2}$
}

\begin{abstract}
Resumo
Este artigo apresenta um modelo metodológico desenvolvido para melhoria dos processos de planejamento e autoavaliação aplicado à gestão de Instituições de Ensino Superior Privadas - IESP. Para tanto, foi realizada uma análise bibliográfica, que resultou em um Modelo de Planejamento Estratégico articulado à autoavaliação institucional, requisito normativo para o processo de regulação do Ensino Superior, instituída pela Lei no 10.861, de 14 de abril de 2004 .
\end{abstract}

Palavras-chave: Instituições de Ensino Superior Privadas. Autoavaliação. Panejamento estratégico.

\begin{abstract}
This paper presents a methodological framework developed to improve the processes of planning and self-assessment applied to the management of Private Higher Education Institutions - IESP. Therefore, we analyzed literature which resulted in a Model of Strategic Planning articulated institutional self-evaluation, regulatory requirements for the regulation process of Higher Education, established by Law $n^{\circ}$ 10.861, dated april 14, 2004.
\end{abstract}

Keywords: Private Institutions of Higher Education. Self-assessment. Strategic planning.

\section{Introdução}

A intensidade e diversidade das mudanças contemporâneas e a expansão das instituições de ensino, resultado das políticas públicas de democratização do acesso à educação superior, configuram novos desafios aos Gestores de Instituições de Ensino Superior Privadas (IESP). No cenário brasileiro, das 2.378

\footnotetext{
${ }^{1}$ Especialista em Gestão Educacional: Supervisão e Orientação Educacional. josiasmazzurana@gmail.com

2 Pós-Doutor em Engenharia de Produção. Professor do Mestrado em Desenvolvimento Regional da Faccat. carlosfernandojung@gmail.com
} 
instituições de ensino superior, 88,3\% são privadas; destas, 85,2\% são faculdades; em relação às Instituições Federais, no período de 2001 a 2010, estas apresentam um aumento de $140,5 \%$ relativamente ao número de ingressantes, definindo maior competitividade às Instituições de pequeno porte (INEP, 2010).

Neste contexto, o planejamento Estratégico, como ferramenta de gestão, adquire nova importância como resposta ao mercado competitivo, representando o comprometimento com o futuro da IES, e somente terá sentido com a sua implementação (MEYER JÚNIOR; SERMANN; MANGOLIM, 2004).

Para isso, torna-se necessário o comprometimento integrado dos sujeitos (gestores, comunidades acadêmicas e civis organizadas), para a constituição de objetivos e estratégias, de acordo com a realidade institucional (VIANNA, 2004).

A ação inicial para a implementação do Planejamento Estratégico é a análise do ambiente organizacional, configurada pela identificação do contexto em que a IES está inserida e sua situação estratégica (MAXIMIANO, 2004).

Desta forma, a pesquisa proposta tem por objetivo a reflexão sobre o processo de autoavaliação, instituído pela Lei oㅜ 10.861, de 14 de abril de 2004, que possui como finalidade o desenvolvimento de conhecimentos sobre a própria IES, como componente do planejamento estratégico.

Por meio da revisão bibliográfica, buscou-se contemplar os aspectos fundamentais do tema e, como resultado, é apresentada uma proposição de Modelo de Planejamento Estratégico para Instituições de Ensino Superior Privadas - IESP, a partir do Modelo de Rojo (2001), com o objetivo de subsidiar pesquisas futuras, relacionadas ao Planejamento Estratégico articulado com a autoavaliação. $O$ artigo estrutura-se da seguinte forma: na seção 2, é apresentada a fundamentação teórica; na seção 3 , os procedimentos metodológicos, e a seção 4 traz as considerações finais.

\section{Fundamentação Teórica}

\subsection{Concepções sobre Planejamento Estratégico}

Devido a mudanças sociais, políticas e econômicas que afetam a sociedade contemporânea, a Gestão do Ensino Superior, nos últimos anos, adquire novo e 
importante papel. O cenário mais competitivo, relacionado à expansão das Instituições de Ensino, principalmente a partir da década de 1990, exige reflexões sobre as questões estratégicas (DOURADO; CATANI; MANCEBO; OLIVEIRA, 2003; FILHO 2009; LIMA; TOMIELLO; SILVEIRA, 2004).

Nesse contexto, o Planejamento estratégico torna-se fundamental para o desenvolvimento organizacional, uma vez que fomenta reflexões em torno dos princípios básicos que definem a instituição, a missão, a visão, as políticas, os objetivos (LIMA; TOMIELLO; SILVEIRA, 2004).

Para Oliveira (2009), a natureza que constitui o planejamento estratégico também o configura como complexo, por considerar, em processo contínuo, o futuro organizacional. Para isso, deve ponderar o contexto no qual a organização está inserida, pois o planejamento, ao projetar à frente os objetivos, está afeto à conjuntura em que a organização se encontra.

Como componentes principais do processo de elaboração do planejamento estratégico, formalizados a partir de análises e decisões, Maximiano (2004) define: i) análise da situação estratégica; ii) análise do ambiente externo; iii) análise dos pontos fortes e fracos; iv) definição de objetivos e estratégias; v) estratégias funcionais e operacionais; vi) execução e avaliação.

$\mathrm{Na}$ sequência, apresenta-se o detalhamento de tais etapas:

i) Análise da situação estratégica: seu objetivo é o diagnóstico da circunstância estratégica em que se encontra a organização, tendo por principais pontos a missão, o desempenho, as vantagens competitivas e as estratégias vigentes;

ii) Análise do ambiente: representa um dos pontos essenciais do planejamento. Considerando que a maior competitividade que configura o cenário contemporâneo afeta o desempenho da organização, a análise do contexto torna-se imprescindível para o desenvolvimento institucional. Como elementos fundamentais a serem considerados para a análise, destacam-se ramos de negócio, mudanças tecnológicas, ação e controle do governo, conjuntura econômica e tendências sociais;

iii) Análise dos pontos fortes e fracos: compreende o meio de identificação dos processos da organização, sua capacidade e limitações, podendo ser identificados a partir da avaliação de desempenho, incidindo na 
elaboração das estratégias. A análise dos pontos fortes e fracos deve considerar a análise das áreas funcionais e os projetos benchmarking ${ }^{3}$.

iv) Definição de objetivos e estratégias: como resultado da identificação das ameaças, oportunidades, fraquezas e potencialidades, esta etapa compreende ações para a efetivação do Planejamento, estratégias que visam cumprir os objetivos definidos a partir do alinhamento com a situação estratégica, a missão e a visão.

v) Estratégias funcionais e operacionais: configuram o curso das ações, como o objetivo de realização da missão e objetivos; a organização define as estratégias, que consistem em determinar ações sistematizadas, permitindo a efetividade do Plano Estratégico; e

vi) Execução e Avaliação: a execução do planejamento dá-se pela efetivação dos planos táticos e operacionais; sua avaliação deve permitir o monitoramento do desenvolvimento do Plano Estratégico, possibilitando reflexões e aprimoramentos dos objetivos e das estratégias institucionais.

Maximiano (2004) conceitua, a partir dessas etapas, o planejamento como ferramenta de reflexões, que deve subsidiar decisões comprometidas com o futuro da organização.

Bateman e Snell (1998) definem o conceito de planejamento estratégico como processo contínuo e racional para a tomada de decisões. Em seu modelo de processo de administração estratégica, trata das principais etapas do Planejamento Estratégico, constituído por: i) estabelecimento de uma missão e uma visão; ii) análise ambiental; iii) avaliação interna; iv) formulação de estratégias; v) implementação de estratégias e vi) controle estratégico. As etapas são, a seguir, descritas:

i) Estabelecimento da missão e visão: constituída com o objetivo de definir a razão da existência da IES em seu contexto, a missão institucional estabelece a finalidade e a razão de ser da organização. No entanto, a visão Institucional perpassa a missão, pois promove a perspectiva e o direcionamento da organização, configurando-a por meio de seus objetivos e almejos, traduzindo as intenções e aspirações futuras;

\footnotetext{
${ }^{3}$ Técnica pela qual uma organização compara seu desempenho com outra (MAXIMIANO, 2004). 
ii) Análise ambiental: configura-se como um dos fatores críticos para a elaboração do Planejamento Estratégico, constituída pelo exame da organização e do ambiente em que está inserida; trata-se da avaliação interna (pontos fortes e fracos) e externa (oportunidades e ameaças), que poderá ser desenvolvida através da análise SWOT4 (BATEMAN; SNELL, 1998; SCHERMERHORN, 2006; MACHADO, 2008; MAXIMIANO, 2004);

iii) Avaliação interna: configura-se pelo panorama das competências e recursos da organização. Como componentes básicos, destacam-se análise financeira, de recursos humanos, de marketing, de produção e operações;

iv) Formulação de estratégias: decorrentes do diagnóstico da análise ambiental, que descreve a realidade da organização, devem formular caminhos que estabeleçam a direção de ações em decorrência dos objetivos;

v) Implementação de estratégias: configura-se como desafio ao gestor, devendo considerar, além das análises dos fatores externos e internos, a estrutura, a tecnologia, os recursos humanos, a liderança e a cultura da instituição, além do comprometimento dos sujeitos, este, fator imprescindível para o sucesso de execução das estratégias.

Rojo (2001), ao considerar a dinâmica da sociedade contemporânea, que define o cenário de maior competitividade das instituições de Ensino Superior, apresenta um modelo de Planejamento Estratégico voltado para Instituições de Ensino Superior Privadas. Ver Figura 1:

\footnotetext{
${ }^{4}$ Ferramenta utilizada para a análise ambiental, sendo subsídio para a Gestão e o Planejamento Estratégico. O termo deriva de quadro palavras em inglês: Strengths (Forças), Weaknesses (Fraquezas), Opportunities (Oportunidades) e Threats (Ameaças).
} 
Figura 1 - Modelo de Planejamento Estratégico para IES privadas, segundo Rojo (2001)

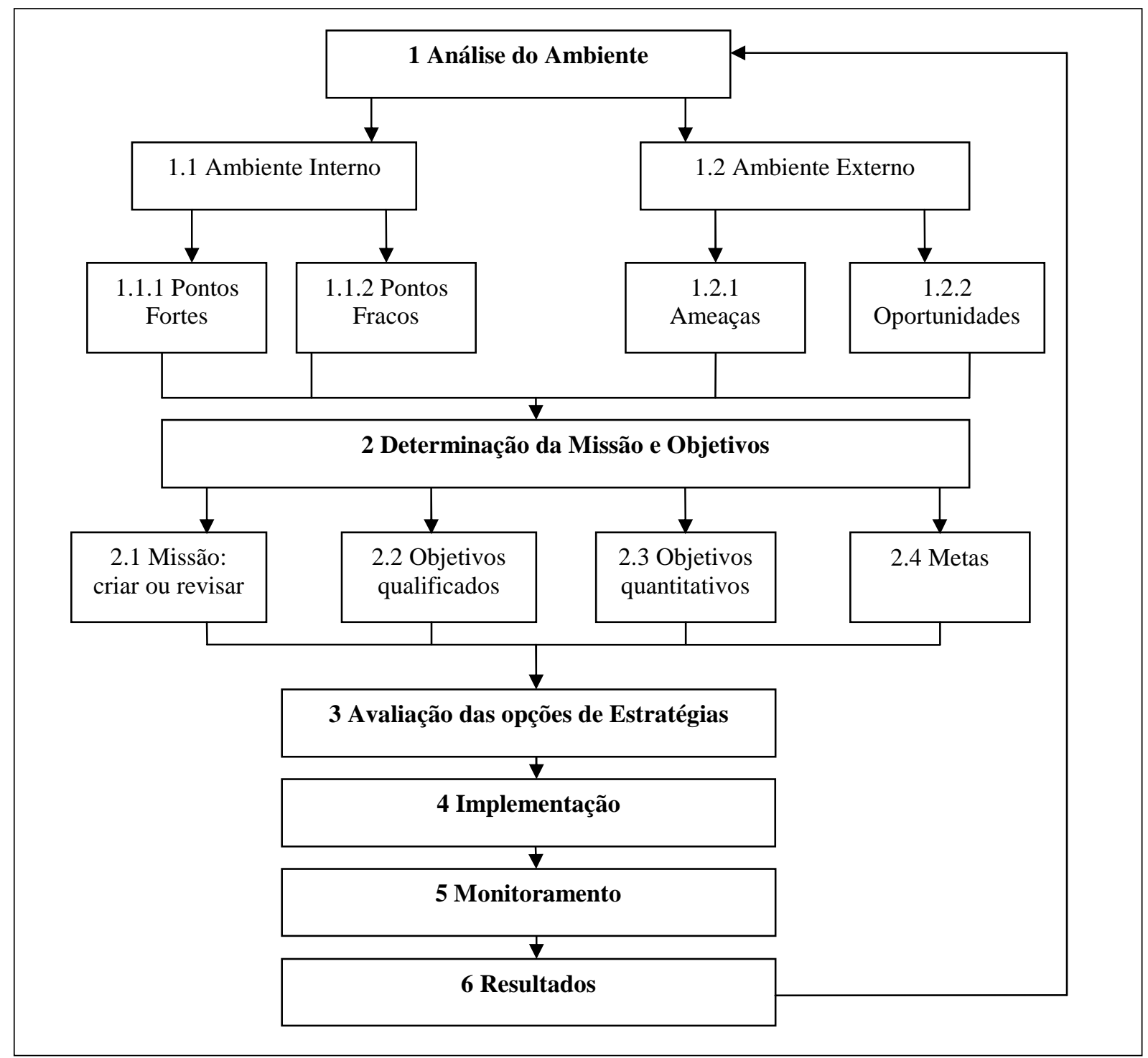

Fonte: Elaborado pelos autores com base em Rojo (2001).

1. Análise do Ambiente: permite obter informações do contexto em que a Instituição de Ensino Superior (IES) está inserida, constituindo-se do diagnóstico dos ambientes interno e externo. Para o ambiente interno (1.1), sua análise deve permitir identificar dados que caracterizam a IES, considerando sua estrutura, corpo docente, discente e técnico administrativo; o grau de satisfação dos alunos, entre outros elementos que possam permitir a análise de pontos Forte (1.1.1) e Fracos (1.1.2) da instituição. Em relação ao ambiente externo (1.2), sua avaliação deve considerar fatores que afetam o desempenho da IES, resultado do 
contexto histórico em que se encontra, sendo elementos incontroláveis pela instituição. Assim, a análise do contexto externo deve ser constituída pela identificação das ameaças (1.2.1) e oportunidades (1.2.2);

2. Determinação da Missão e Objetivos: a missão (2.1), considerando o contexto identificado pelas análises dos ambientes interno e externo, deve passar por um processo de reflexão, permitindo rever a razão de ser da IES. Os objetivos são enquadrados em qualitativos (2.2), que permitam a mensuração, e quantitativos (2.3). As metas (2.4) estão associadas aos objetivos, considerando o tempo de realização e as prioridades;

3. Avaliação das opções de Estratégias: deve considerar todas as implicações levantadas pela análise ambiental, considerando o cenário, a missão e as metas, a fim de que se possa optar pela estratégia mais assertiva para atingir os objetivos;

4. Implementação: com o foco nos objetivos, em consonância com a missão, a implementação representa a efetivação das estratégias.

5. Monitoramento: incide no acompanhamento da execução das estratégias e das implicações em relação à implementação;

6. Resultados: consiste na análise de dados, incidindo na revisão de todos os componentes do processo.

Segundo Rojo (2001), o Planejamento Estratégico, por considerar a organização como um todo e analisar uma gama complexa de fatores, amplia o conceito de planejar, configura-se pela formalização de um processo e pelo estabelecimento de estratégias que possibilitem cumprir a missão e a visão institucional.

Como importante ferramenta de gestão, o planejamento estratégico permite o equilíbrio das tomadas de decisões, considerando o contexto em que a organização está inserida, pois oportuniza a reflexão dos fatores ambientais, analisando variáveis internas e externas. Para Maximiano (1995), o planejamento estratégico torna-se essencial para a) enfrentar fatos que certamente ocorrerão; b) criar um futuro desejável; c) coordenar fatos entre si. Desta forma, considerando as mudanças do cenário nacional procedentes do processo de globalização, o planejamento estratégico permite olhar, de forma sistemática, para o futuro, com o objetivo de assegurar o desenvolvimento da organização. 
Entre maio e abril de 2003, o Secretário de Educação Superior do Ministério da Educação - SESu/MEC, Carlos Roberto Antunes dos Santos, emite as Portarias ํo 11 e ํo 19, que instituem a Comissão Especial da Avaliação da Educação Superior (CEA), presidida pelo professor José Dias Sobrinho (Universidade Estadual de Campinas - Unicamp), com a finalidade de rever processos, políticas e instrumentos de Avaliação da Educação Superior (INEP, 2009). Data não coincide

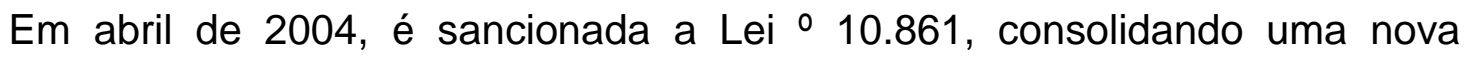
dinâmica de avaliação do ensino superior, integrando os processos de avaliação das instituições, cursos e estudantes. O Sistema Nacional de Avaliação da Educação Superior (SINAES) busca, de forma integrada, a avaliação de Instituições, cursos e estudantes, tendo por objetivo a melhoria da qualidade do ensino superior e sua expansão, o aumento permanente da sua eficácia institucional e a efetividade acadêmica. Por meio da consolidação da autonomia institucional, tende a afirmação do respeito à diversidade, e o efetivo aprofundamento da responsabilidade social das IES (Lei no 10.861/2004). Para isso, com base no Artigo 3ํ, da Lei 10.861/2004, o SINAES estrutura-se em dez dimensões:

Art. 3ํ A avaliação das instituições de educação superior terá por objetivo identificar o seu perfil e o significado de sua atuação, por meio de suas atividades, cursos, programas, projetos e setores, considerando as diferentes dimensões institucionais, dentre elas obrigatoriamente as seguintes:

I - a missão e o plano de desenvolvimento institucional;

II - a política para o ensino, a pesquisa, a pós-graduação, a extensão e as respectivas formas de operacionalização, incluídos os procedimentos para estímulo à produção acadêmica, as bolsas de pesquisa, de monitoria e demais modalidades;

III - a responsabilidade social da instituição, considerada especialmente no que se refere à sua contribuição em relação à inclusão social, ao desenvolvimento econômico e social, à defesa do meio ambiente, da memória cultural, da produção artística e do patrimônio cultural;

IV - a comunicação com a sociedade;

V - as políticas de pessoal, as carreiras do corpo docente e do corpo técnico-administrativo, seu aperfeiçoamento, desenvolvimento profissional e suas condições de trabalho;

VI - organização e gestão da instituição, especialmente o funcionamento e representatividade dos colegiados, sua independência e autonomia na relação com a mantenedora, e a participação dos segmentos da comunidade universitária nos processos decisórios;

VII - infraestrutura física, especialmente a de ensino e de pesquisa, biblioteca, recursos de informação e comunicação. 
Prosseguindo:

VIII - planejamento e avaliação, especialmente os processos, resultados e eficácia da autoavaliação institucional;

IX - políticas de atendimento aos estudantes;

$X$ - sustentabilidade financeira, tendo em vista o significado social da continuidade dos compromissos na oferta da educação superior(Lei $\mathrm{n}^{\circ}$ 10.861/2004).

A Avaliação do ensino superior, atendendo ao SINAES, divide-se em três modalidades: Avaliação Institucional (interna e externa), Avaliação de Curso e o Exame Nacional de Avaliação do Desempenho dos Estudantes - ENADE (BRASIL, 2012).

Às IES cabe a responsabilidade pela autoavaliação institucional, segundo a Lei no 10.861/2004,

Art. 11 Cada instituição de ensino superior, pública ou privada, constituirá Comissão Própria de Avaliação - CPA, no prazo de 60 (sessenta) dias, a contar da publicação desta Lei, com as atribuições de condução dos processos de avaliação internos da instituição, de sistematização e de prestação das informações solicitadas pelo INEP, obedecidas as seguintes diretrizes:

1 - constituição por ato do dirigente máximo da instituição de ensino superior, ou por previsão no seu próprio estatuto ou regimento, assegurada a participação de todos os segmentos da comunidade universitária e da sociedade civil organizada, e vedada a composição que privilegie a maioria absoluta de um dos segmentos;

II - atuação autônoma em relação a conselhos e demais órgãos colegiados existentes na instituição de educação superior.

Em julho de 2004, é publicada, no Diário Oficial da União, a Portaria oo $2.051^{5}$, do Ministério da Educação - MEC, que regulamenta os procedimentos de avaliação do Sistema Nacional de Avaliação da Educação Superior (SINAES), e, em relação à autoavaliação, delibera:

Art. $7^{\circ}$ As Comissões Próprias de Avaliação (CPAs), previstas no Art. 11 da Lei no 10.861, de 14 de abril de 2004, e constituídas no âmbito de cada instituição de educação superior, terão por atribuição a coordenação dos processos internos de avaliação da instituição, de sistematização e de prestação das informações solicitadas pelo INEP.

Este artigo dá outras informações:

\footnotetext{
${ }^{5}$ Revogada em 2010, após a republicação da Portaria Normativa MEC no 40/2007.
} 
$\S 1^{\circ}$ As CPAs atuarão com autonomia em relação a conselhos e demais órgãos colegiados existentes na instituição de educação superior;

$\S 2^{\circ}$ A forma de composição, a duração do mandato de seus membros, a dinâmica de funcionamento e a especificação de atribuições da CPA deverão ser objeto de regulamentação própria, a ser aprovada pelo órgão colegiado máximo de cada instituição de educação superior, observando-se as seguintes diretrizes:

I - necessária participação de todos os segmentos da comunidade acadêmica (docente, discente e técnico-administrativo) e de representantes da sociedade civil organizada, ficando vedada a existência de maioria absoluta por parte de qualquer um dos segmentos representados;

II - ampla divulgação de sua composição e de todas as suas atividades.

Vinculada ao processo de regulação, a autoavaliação é instrumento essencial e obrigatório para que a IES se integre formalmente ao sistema regular da Educação Superior (INEP, 2009). Para isso, a Portaria Normativa MEC no 40, de 12 de dezembro de $2007^{6}$, dispõe:

Art. 61-D Será mantido no cadastro e-MEC, junto ao registro da instituição, campo para inserção de relatório de auto-avaliação, validado pela CPA, a ser apresentado até o final de março de cada ano, em versão parcial ou integral, conforme se trate de ano intermediário ou final do ciclo avaliativo.

Os relatórios devem apresentar dados relacionados a ações de caráter pedagógico e administrativo resultantes do processo de autoavaliação, e indicadores necessários para melhorias das carências identificadas, devendo subsidiar os processos de recredenciamento de IES e de autorização, reconhecimento e renovação de reconhecimento de cursos. (Portaria Normativa MEC nํ 40/2007)

O processo de autoavaliação com a participação expressiva da comunidade, a qual está afeta direta ou indiretamente às ações da IES, torna o processo mais significativo e democrático. Dessa forma, a autoavaliação configura-se pela participação plural da comunidade acadêmica e externa, em um processo social de reflexão e construção de conhecimentos sobre a Instituição que possibilitem transformações (INEP, 2009).

\subsection{Instituições de Ensino Superior, Planejamento Estratégico e Autoavaliação}

As organizações sociais, assim como as Instituições de Ensino Superior - IES,

\footnotetext{
${ }^{6}$ Republicada em 29/12/2010, Seção 1, p. 23, por ter saído no DOU no 239, de 13/12/2007, Seção 1 , p. 39, com incorreção no original.
} 
são partes integrantes de um novo contexto, no qual a sociedade contemporânea, de características mais dinâmicas, relacionadas a fatores econômicos, políticos, culturais e tecnológicos, além de um cenário mais competitivo, exige o posicionamento estratégico por parte da Gestão (MEYER JÚNIOR; SERMANN; MANGOLIM, 2004).

O Planejamento Estratégico, neste contexto, busca preparar a Instituição às mudanças do ambiente e à competitividade, representando importante ferramenta gerencial, com métodos do processo administrativo, que permitem a idealização do futuro, com o dever de cumprir a missão e visão institucional (LIMA; TOMIELLO; SILVEIRA, 2004; PAPA FILHO, 2009).

Dessa forma, o planejamento estratégico configura-se pelo compromisso com o futuro da organização; quando formalizado, permite, através de suas etapas de elaboração, o conhecimento da realidade, do cenário, dos recursos, das potencialidades e limitações, fomentando o desenvolvimento de ações que possibilitem maior racionalidade administrativa. (PAPA FILHO, 2009).

Por vez, consciente da importância do Planejamento, não somente para a estabilidade da Instituição, como para o desenvolvimento do ensino de qualidade e afirmação de seu compromisso social, o Estado, desde março de 2002, com a publicação da Resolução no $10^{7}$, do Conselho Nacional da Educação - CNE e Secretaria de Educação Superior - SESu, torna obrigatória a elaboração do Plano de Desenvolvimento Institucional - PDI, como requisito básico para o pleno funcionamento das Instituições de Ensino Superior, públicas e privadas. A implementação do Plano de Desenvolvimento Institucional possibilita aos Gestores a reflexão sobre as principais questões atinentes à instituição (MEYER JÚNIOR; SERMANN; MANGOLIM, 2004; CARDOSO, 2006).

Com o objetivo de permitir a expansão do ensino superior, em 2003, acirramse os debates frente à Reforma Universitária, com o compromisso com a qualidade e inclusão, discutindo-se a necessidade de políticas públicas que possibilitem aferir as condições do sistema nacional de ensino superior (ANDRIOLA, 2009).

Em abril de 2004, é instituído o Sistema Nacional de Avaliação da Educação

\footnotetext{
${ }^{7}$ Revogada pela Resolução CNE/CES n. ${ }^{\circ} 11$, de 10 de julho de 2006. No entanto, o PDI permanece como requisito básico para os processos de Regulação, Supervisão e Avaliação, segundo o Decreto Executivo ํo 5.773/2006.
} 
Superior (SINAES), a partir da Lei no 10.861. Esta estabeleceu a autoavalição institucional como requisito para o processo de regulação do Ensino Superior, ao mesmo tempo em que torna compulsório às Instituições de Ensino Superior (IES) a constituição de uma Comissão Própria de Avaliação (CPA), responsável pela condução deste processo, que conta com a participação da comunidade acadêmica ${ }^{8}$ e civil organizada.

Destaca-se a autovaliação como um processo que visa à melhoria da qualidade do ensino, diante de um processo de participação coletiva, através de princípios democráticos, que possibilitem a visão multilateral sobre IES, permitindo a reflexão por parte das diferentes percepções, seja docente, discente, administrativa e social. Uma vez efetiva, a autoavaliação representa uma ferramenta imprescindível para a Gestão do Ensino Superior, sendo, também, subsídio para o aperfeiçoamento do Plano de Desenvolvimento Institucional e Projetos Pedagógicos de cursos (ANDRIOLA, 2009; GALDINO, 2011).

Porém, para que autoavaliação se consolide como subsídio para a Gestão, é essencial que as etapas da avaliação interna ocorram contemplando a participação plural dos sujeitos, a transparência e o planejamento do processo, permitindo a criação e permanência da cultura avaliativa (GALDINO, 2011).

A autoavaliação, componente para a regulação do ensino superior, possibilita o diagnóstico da realidade interna institucional, subsidiando a gestão estratégica, com vista ao alcance dos objetivos institucionais. Desta forma, a autoavaliação amplia seu significado estratégico, quando da participação da comunidade acadêmica e externa, que fazem da avaliação um instrumento para melhoria contínua da Gestão (MEYER JÚNIOR; SERMANN; MANGOLIM, 2004).

A implementação do Planejamento Estratégico em Instituições de Ensino Superior representa um grande desafio à gestão, diante dos aspectos organizacionais, culturais e financeiros, pois o Planejar compreende a totalidade Institucional, soma-se à complexidade de sua natureza, ou seja, seu produto é o conhecimento. Associado ao processo de autoavaliação, o desafio para a gestão está em integrar todos os segmentos da comunidade comprometidos com a IES, de forma responsável e crítica, considerando as características institucionais. Desta forma, planejar estrategicamente, diante da modernidade e, consequentemente, da competitividade,

\footnotetext{
${ }^{8} \mathrm{~A}$ expressão comunidade acadêmica engloba o corpo docente, discente e técnico-administrativo. 
representa uma exigência às Instituições de Ensino (VIANNA, 2004).

\section{Procedimentos metodológicos}

\subsection{Cenário}

Segundo os dados do Censo da Educação Superior, do ano de 2010, mensurados pelo Instituto Nacional de Estudos e Pesquisa Educacionais Anísio Teixeira (INEP), o total de instituições no Brasil passa de 1.391, em 2001, para 2.378, em 2010 (INEP, 2012).

Esses totais, considerado o ano de realização do Censo, representam $88,3 \%$ de instituições privadas; $4,5 \%$, estaduais; $4,2 \%$, federais e 3,0\%, municipais. Destas, 85,2\% são faculdades; $8,0 \%$ são universidades; $5,3 \%$ são centros universitários e 1,6\% são institutos federais de educação, ciência e tecnologia - IFs - e centros federais de educação tecnológica - Cefets (INEP, 2012).

Segundo os dados do INEP, o setor público apresenta significativa expansão, resultado das políticas públicas de democratização do acesso à educação superior, ao mesmo tempo em que o setor privado apresenta certa estabilização. De 2001 a 2010 , as instituições federais tiveram um aumento de $85,9 \%$ em suas matrículas, e as estaduais, de $66,7 \%$ (INEP, 2012).

Em relação aos ingressantes nos cursos de graduação, em 2010, presencial e a distância, entraram 2.182.229 alunos, representando um aumento de 140,5\% em instituições federais e 115,4\% em instituições privadas (INEP, 2012).

Indagando o índice de Inadimplência no setor de Educação Superior, a pesquisa realizada pela assessoria econômica do Sindicato das Entidades Mantenedoras de Estabelecimentos de Ensino Superior no Estado de São Paulo (Semesp) -, por meio do Sistema de Informações do Ensino Superior Particular Sindata - demonstra que o índice de inadimplência no ensino superior privado, no ano de 2010 , chegou a ser $68 \%$ superior à inadimplência de todos os setores da economia consolidados. Em 2010, a inadimplência total no país foi de $5,7 \%$, enquanto que o setor do ensino superior privado registrou um índice de 9,58\% (SINDICATO, 2011). 
Considerando as informações acima elencadas, pode-se compreender alguns desafios aos Gestores de Instituições de Ensino Superior, especialmente para instituições privadas de pequeno porte, configuradas como Faculdades. As instituições de ensino superior privadas, segundo o relatório do INEP, no ano de 2010, corresponderam a 83,3\% das 2.378 instituições, sendo 85,2\% credenciadas como faculdades (INEP, 2012). A concorrência não está restrita somente a este perfil de IES, acrescenta-se à expansão, de 2001 a 2010, das instituições federais, que tiveram um aumento de $85,9 \%$, em suas matrículas e $140,5 \%$ no número de ingressantes, em cursos presenciais e a distância (INEP, 2012).

Quanto ao índice de inadimplência, o atraso acima de 90 dias nas mensalidades das instituições de pequeno porte ${ }^{9}$ atingiu $11,63 \%$, em 2010 (SINDICATO, 2011). Outros indicadores que caracterizam o cenário nacional devem ser considerados, a exemplo da taxa de desemprego medida pelo Instituto Brasileiro de Geografia e Estatística (IBGE), nas seis maiores regiões metropolitanas ${ }^{10}$, registrada em agosto de 2012, sendo de 5,3 \% (IBGE, 2012)

Desta forma, o cenário contemporâneo exige das Instituições de Ensino Superior, especialmente das Faculdades Privadas, o posicionamento estratégico.

\subsection{Metodologia}

Os procedimentos para execução da pesquisa têm por princípios metodológicos uma abordagem qualitativa baseada em uma revisão bibliográfica que, segundo Miles e Huberman (1994), consiste em um processo investigativo no qual o pesquisador, gradualmente, compreende o sentido de um fenômeno social ao constatar, comparar, reproduzir, catalogar e classificar o objeto de estudo.

Desta forma, a revisão bibliográfica tem como finalidade contemplar os aspectos fundamentais do tema, por meio da análise, que estabelece a correlação entre Planejamento Estratégico, Autoavaliação e Gestão, viabilizando a descoberta de novos conhecimentos e permitindo a proposição de um modelo aplicado à melhoria dos processos de gestão em Instituições de Ensino Superior Privadas, a

\footnotetext{
${ }^{9}$ A pesquisa do Semesp considerou como instituições de pesqueno porte, aquelas com até dois mil alunos.

${ }^{10}$ Regiões metropolitanas de Recife, Salvador, Belo Horizonte, Rio de Janeiro, São Paulo e Porto Alegre.
} 
partir do Modelo de Planejamento Estratégico de Rojo (2001), para Instituições de Ensino Superior Privadas.

\subsection{Modelo proposto}

O modelo proposto tem por objetivo integrar a autoavaliação institucional ao Planejamento Estratégico de Instituições de Ensino Superior Privadas. O Planejamento configura-se como importante ferramenta de gestão, definindo estratégias com o objetivo de cumprir a visão e a missão institucional, fomentando o sucesso competitivo das IES no atual cenário de mudanças constantes (SCHERMERHOR, 2006). É, portanto, essencial para o desenvolvimento organizacional da Instituição, frente ao mercado competitivo.

Articulada com o processo de Gestão, a autoavaliação, requisito para o processo de regulação do Ensino Superior, estabelecida pela Lei no 10.861 , de 14 de abril de 2004, quando constituída com a finalidade de integrar o Planejamento Estratégico, subsidia a análise ambiental, através do diagnóstico interno da IES. $\mathrm{Na}$ Figura 2, apresentada na próxima página, é apresentado o Modelo de Planejamento Estratégico para Instituições de Ensino Superior Privadas, em forma de diagrama, em seguida, é feita a descrição de suas etapas. 


\section{Figura 2 - Modelo Proposto de Planejamento Estratégico para IES privadas}

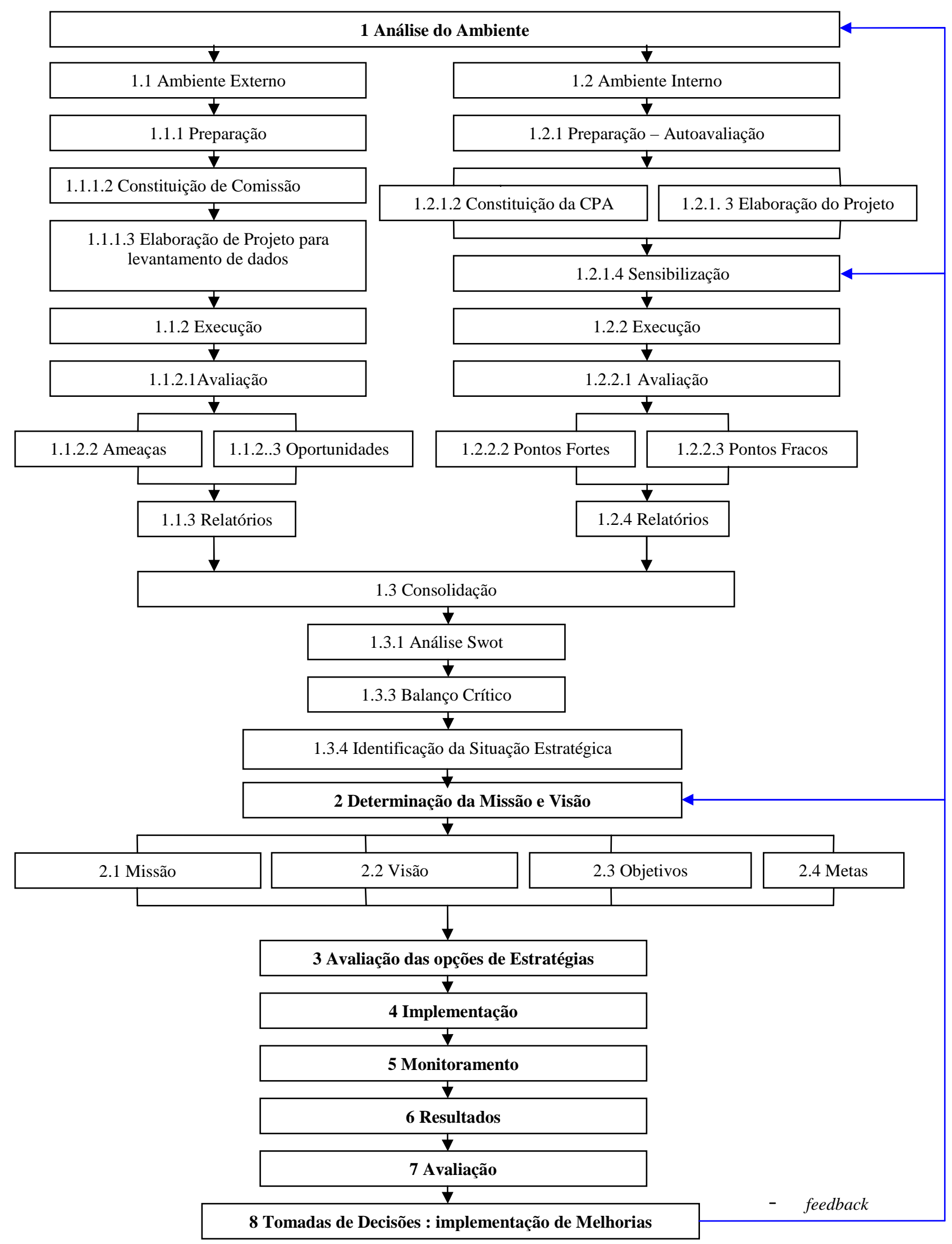

Fonte: Elaborado pelos autores. 
Etapa 1. Análise do Ambiente: compreende um dos pontos-chave do planejamento, permitindo a identificação da Situação Estratégica da Instituição. Seu resultado é o diagnóstico da IES, composto pelo exame da instituição e do ambiente em que está inserida. A avaliação ambiental deve permitir melhor adequação das estratégias aos objetivos, constituindo-se da análise do ambiente externo (1.1) e interno (1.2).

1.1 Ambiente Externo: representa elementos incontroláveis por parte da IES, considerando o contexto no qual a Instituição se encontra, e que interferem em seu desempenho. Por sua amplitude, o ambiente externo caracteriza-se como o componente mais complexo dos segmentos ambientais. $\mathrm{O}$ arranjo deste processo prevê o acontecimento de etapas distintas, para que seja possível identificar as ameaças e oportunidades com precisão; sua preparação (1.1.1) caracteriza-se pela definição de ações e responsáveis. Primeiramente definem-se os integrantes da Comissão de Desenvolvimento do Planejamento (1.1.1.2), responsáveis pela condução do processo, com representantes dos segmentos administrativos e da gestão, com atribuições para definir estratégias, através da elaboração do Projeto, para o levantamento de dados. No Projeto (1.1.1.2), definem-se diretrizes, metodologias, indicadores e instrumentos, observando fatores que definem 0 contexto: socioeconômicos, políticos, culturais, tecnológicos e jurídicos, considerando os objetivos institucionais e alocação de recursos necessários para sua execução (1.1.1.2). Concluída a execução, inicia-se o processo de avaliação (1.1.2.1) das informações coletadas, mensurando as informações em um processo de identificação das ameaças (1.1.2.2) e oportunidades (1.1.2.3), possibilitando a elaboração de relatórios (1.1.3) que definem a situação do ambiente externo.

1.2 Análise do Ambiente Interno: tem por objetivo evidenciar a situação em que se encontra a IES, identificando limitações e potencialidades. A organização deste processo prevê a ocorrência de diferentes etapas, sua preparação (1.2.1) caracteriza-se pelo planejamento das ações, de forma que permita sistematizar os procedimentos e seus responsáveis, fatores necessários para a implementação da avaliação interna. Inicialmente, 
define-se a composição da Comissão Própria de Avaliação - CPA (1.2.1.2), regulamentada pela Lei $n=10.861 / 2004$, que deve contar com representantes da comunidade acadêmica e da sociedade civil organizada, responsáveis por todo o processo de autoavaliação, e em articulação com a administração da IES para alocação de recursos necessários para a execução da avaliação. A elaboração do Projeto de Autoavaliação (1.2.1.3) tem por finalidade a definição dos objetivos, estratégias, procedimentos, prazos, entre outros elementos fundamentais ao processo, além da elaboração de instrumentos e indicadores, considerando a missão e a visão institucional. A sensibilização (1.2.1.4) deve permitir a participação, através de palestras e seminários, da comunidade acadêmica na elaboração da proposta avaliativa. Tais processos subsidiam a execução (1.2.2) da autoavaliação e avaliação, uma vez que o sujeito se autoavalia e avalia o objeto da avaliação, observando as ações previstas no projeto, nos instrumentos, em coerência com a implementação. Concluída esta etapa, inicia-se a avaliação (1.2.2.1) das informações coletadas, com o foco na identificação dos pontos fortes (1.2.2.2) e fracos (1.2.2.3), resultando na elaboração dos relatórios (1.2.3). Finalizados os relatórios da análise ambiental externa (1.1) e interna (1.2), a comissão responsável pelo planejamento, configurada na análise ambiental externa, assume as demais etapas, entre elas o processo de consolidação das informações coletadas (1.3), composto pela análise Swot (1.3.1), articulando as oportunidades, as ameaças, os pontos fortes e fracos ao prazo, ao grau de impacto e às consequências sobre a IES. Em seguida, relacionam-se as oportunidades aos pontos fortes e as ameaças, aos pontos fracos, subsidiando o Balanço Crítico (1.3.3), permitindo identificar a situação estratégica da Instituição (1.3.4).

Etapa 2. Determinação da missão e visão: considerando a situação estratégica identificada através da análise ambiental (1), consolidada pelo Balanço Crítico (1.3.3), a missão (2.1), razão de ser da Instituição, e a visão (2.2), projeção futura da IES, devem passar por um processo de reflexão que pode resultar na redefinição 
destes valores. Os objetivos (2.3), alinhados à missão, visão e situação estratégica consistem em almejos (qualitativos) que a instituição tem a alcançar. As metas (2.4) correspondem à quantificação destes objetivos, que incidem em estratégias que se caracterizam por ações que permitam atingir tanto os objetivos, quanto as metas;

Etapa 3. Avaliação das opções de Estratégias: deve possibilitar a identificação das estratégias apropriadas ao contexto da IES, considerando as implicações apontadas pela análise ambiental (1), com a finalidade de cumprir com os objetivos e metas, resultando em planos de ações. Estes se configuram em plano tático, que compreende o detalhamento de ações a partir das estratégias, por áreas e setores, e plano operacional, que concebe a efetividade das ações propostas no plano tático.

Etapa 4. Implementação: representa a efetivação do planejamento, sendo necessário considerar os recursos financeiros e infraestrutura, além do comprometimento dos sujeitos. Neste processo, observam-se as ações previstas e a coerência com o Plano de ação.

Etapa 5. Monitoramento: assegura, através do processo de acompanhamento do desenvolvimento do Plano Estratégico, o alinhamento entre ações, objetivos e metas.

Etapa 6. Resultados: consiste no desfecho das ações implementadas, em dados qualitativos dos objetivos e quantitativos das metas alcançadas, constituindo um dos elementos do diagnóstico do Planejamento, identificado na avaliação do desenvolvimento.

Etapa 7. Avaliação: caracteriza-se pela análise do processo desenvolvido, dos resultados alcançados, das estratégias utilizadas, dos obstáculos e dos avanços, permitindo o planejamento de ações futuras, subsidiando a tomada de decisões.

Etapa 8. Tomadas de Decisões - implementação de melhorias: compreende um dos pontos de maior importância do Planejamento Estratégico, configurando-se pela materialização das ações, produzindo significado à participação dos sujeitos envolvidos e ao processo, tornando a IES mais competitiva no mercado, retroalimentando o sistema, uma vez que, ocorrendo mudanças, altera-se a Situação 
Estratégica da IES.

O Modelo de Planejamento Estratégico, aqui apresentado, pretende destacar a importância do processo de autoavaliação, compreendido como diagnóstico da realidade interna da IES, como subsídio para a elaboração do Planejamento Estratégico em Instituições de Ensino Superior Privadas em contribuição com a Gestão Estratégica.

\section{Considerações finais}

A sociedade contemporânea caracteriza-se pela dinâmica das relações políticas, econômicas, sociais, culturais e tecnológicas. Neste contexto de mudanças, a Gestão do Ensino Superior passa a enfrentar novos desafios, tornando necessárias reflexões no âmbito estratégico.

Neste mesmo cenário, os conceitos tradicionais de avaliação tornam-se incapazes de oferecer resultados satisfatórios. Diante desta concepção, os processos avaliativos estendem-se a vários domínios do Estado, principalmente nas políticas públicas voltadas à Educação. A diversificação e ampliação histórica das práticas avaliativas destacam sua importância política. Em 2004, é instituído o Sistema Nacional de Avaliação da Educação Superior (SINAES), compreendendo a autoavaliação como requisito normativo para o processo de regulação do Ensino Superior.

A autoavaliação representa a reflexão sobre a própria IES, gera conhecimentos fundamentais para a melhoria dos procedimentos internos e, quando constituída com a finalidade de integrar o Planejamento, permite subsidiar a elaboração do diagnóstico institucional, por meio da análise do ambiente interno, componente da análise ambiental que oportuniza identificar a situação estratégica da IES, fator fundamental para o desenvolvimento do Planejamento.

O Planejamento Estratégico representa o comprometimento dos Gestores com o futuro da Instituição, compreendendo-a em sua globalidade, a partir da reflexão de sua situação estratégica, de seus objetivos e metas, alinhados à missão e visão institucional.

Com a finalidade de assegurar o desenvolvimento institucional, através de melhorias dos processos, das atividades administrativas, pedagógicas e da 
infraestrutura, assim como a autoavaliação, o Planejamento Estratégico deve contar com a participação da comunidade acadêmica e da sociedade.

A autoavaliação, pela dificuldade de se atribuir significado e identidade ao processo, assim como a participação, esta principalmente em relação ao Planejamento Estratégico, quando definido em moldes tradicionais, representam desafios à Gestão. O Modelo de Planejamento Estratégico proposto deverá permitir que esses desafios sejam minimizados, quando considerada a autoavaliação institucional como componente do Planejamento. Esta integração, além de tornar o processo mais participativo, torna-o coerente com o histórico social da IES, além de possibilitar mudanças na cultura organizacional da Instituição, fomentando a cultura avaliativa e o comprometimento dos sujeitos, a partir da implementação de melhorias, resultado da efetivação do Planejamento.

A presente pesquisa teve por objetivo articular a autoavaliação institucional ao Planejamento Estratégico, desenvolvida através da revisão bibliográfica, que resultou na proposição de um modelo de Planejamento Estratégico para Instituições de Ensino Superior Privadas. É importante destacar que a pesquisa não teve por finalidade esgotar as reflexões sobre o tema, mas subsidiar pesquisas futuras.

\section{Referências}

ANDRIOLA, Wagner Bandeira. Planejamento Estratégico e Gestão Universitária como atividades oriundas da auto-avaliação de instituições de ensino superior (IES): o exemplo da universidade federal do ceará (ufc). Revista lberoamericana de Evaluación Educativa 2009. vl. 2, n 2. p. 82-103.

BATEMAN, Thomas S; SNELL, Scott A. Administração: construindo vantagem competitiva. São Paulo, Atlas, 1998.

BRASIL. Executivo. Lei no 10.861, de 14 de abril de 2004. Institui o Sistema Nacional de Avaliação da Educação Superior - SINAES e dá outras providências. Disponível em: <planalto.gov.br >.Acesso em: 10 ago. 2012b . Instituto de Estudos e Pesquisas Educacionais Anísio Teixeira. SINAES Sistema Nacional de Avaliação da Educação Superior: da concepção à regulamentação. 5 ed. Brasília; 2009. 
Superior. Brasília, 2004.

. Comissão Nacional de Avaliação da Educação Superior (CONAES). Documento orientador das comissões de avaliação in loco. Brasília, 2012a.

. Comissão Nacional de Avaliação da Educação Superior

(CONAES). Instituto Nacional de Estudos e Pesquisas Educacionais (INEP). Orientações Gerais para o Roteiro da Auto-Avaliação das Instituições. 2004.

Disponível em: <inep.gov.br>. Acesso em: 10 agosto. 2012.

Portaria Normativa № 40, de 12 de dezembro de 2007. Institui o eMEC, sistema eletrônico de fluxo de trabalho e gerenciamento de informações relativas aos processos de regulação, avaliação e supervisão da educação superior no sistema federal de educação, e o Cadastro e-MEC de Instituições e Cursos Superiores e consolida disposições sobre indicadores de qualidade, banco de avaliadores (Basis) e o Exame Nacional de Desempenho de Estudantes (ENADE) e outras disposições. Republicada em 29/12/2010, Seção 1, p. 23, por ter saído no Diário Oficial da União no 239, de 13/12/2007, Seção 1, p. 39, com incorreção no original.

. Secretaria de Educação Superior - SESu. Portaria no 11, de 28 de abril de 2003. Institui Comissão Especial com a finalidade de analisar, oferecer subsídios, fazer recomendações, propor critérios e estratégias para a reformulação dos processos e políticas de avaliação do ensino superior e elaborar a revisão crítica dos seus instrumentos, metodologias e critérios utilizados. Publicada no Diário Oficial da União em 30/04/2003, Seção 1, p. 19.

Secretaria de Educação Superior - SESu. Portaria no 19, de 27 de maio de 2003. Designa professores para integrarem a Comissão Especial, instituída pela Portaria MEC/SESu, n 11, de 28 de abril de 2003, publicada no DOU de 30 de abril de 2003, seção 2, p. 19. Publicada no Diário Oficial da União em 28/05/2003 , Seção 1 p. 11

CARDOSO, Wille Muriel. O Impacto do Plano de Desenvolvimento Institucional na Profissionalização das Instituições Privadas de Ensino Superior. Dissertação (Mestrado em Administração) - Faculdades Integradas de Pedro Leopoldo, Belo Horizonte, 2006.

DOURADO, Luiz Fenandes; CATANI, Afrânio Mendes; MANCEBO, Deise; OLIVEIRA, João Ferreira de (Org.) Políticas e Gestão da Educação Superior: transformações recentes e debates atuais. São Paulo: Xamã, 2003.

GALDINO, Mary Neuza Dias. A Autoavaliação Institucional no Ensino Superior como Instrumento de Gestão. Fundação CESGRANRIO/ Universidade do Grande Rio. 2011. XXV Simpósio Brasileiro Il Congresso IBERO-AMERICANO de Políticas e Administração da Educação. Jubileu de Ouro da ANPAE, no período de 26 a 29 de abril de 2011. 
INSTITUTO Brasileiro de Geografia Estatística - IBGE. Pesquisa Mensal de Emprego. Disponível em:

<ttp://www.ibge.gov.br/home/presidencia/noticias/noticia_visualiza.php?id_noticia=22 20\&id_pagina=1. Acesso em: 11 out. 2012.

INSTITUTO Nacional de Estudos e Pesquisas Educacionais Anísio Teixeira INEP. Censo da educação superior: 2010 - resumo técnico. Brasília: Instituto Nacional de Estudos e Pesquisas Educacionais Anísio Teixeira, 2012.

LIMA, Arnaldo José de; TOMIELLO, Naira; SILVEIRA, Rosana Rosa. Metodologias de Planejamento Estratégico: uma discussão preliminar para IES. IV Colóquio Internacional sobre Gestão Universitária na América do Sul. Florianópolis, 8 a 10 de dezembro de 2004. Disponível em: <http://www.inpeau.ufsc.br/coloquio04/area1.htm>. Acesso em: 24 set. 2012.

MACHADO, Luiz Eduardo. Gestão Estratégica para Instituições de Ensino Superior. Rio de Janeiro: FGV, 2008,

MAXIMIANO, Antonio César Amaru. Introdução à Administração. 4. ed. São Paulo: Atlas, 1995. . Introdução à Administração. 6. ed. São Paulo: Atlas, 2004.

MEYER JÚNIOR; Victor; SERMANN, Lúcia I. C; MANGOLIM Lúcia. Planejamento e Gestão Estratégica: viabilidade nas IES. IV Colóquio Internacional sobre Gestão Universitária na América do Sul. Florianópolis, 8 a 10 de dezembro de 2004. Disponível em: <http://www.inpeau.ufsc.br/coloquio04/area1.htm>. Acesso em: 24 set. 2012.

MILES, M. B.; HUBERMAN, A. M. Qualitative da analysis: a sourcebook of new methods (2nded.). Newbury Park, CA: Sage. 1994. In: CRESWELL, John W. Projetos de pesquisa: métodos qualitativos, quantitativos e misto. 2. ed. Porto Alegre: Artmed, 2007.

OLIVEIRA, Djalma de Pinho Rebouças de. Planejamento Estratégico: conceitos, metodologias e práticas. 26. ed. São Paulo, Atlas, 2009;

PAPA FILHO, Sudário. Planejamento Estratégico em Instituições de Ensino Superior. In: GOULART, Íris Barbosa; PAPA FILHO, Sudário (Coord.). Gestão de Instituições de Ensino Superior. Curitiba: Juruá, 2009;

ROJO, Claudio Antonio. Diagnóstico Ambiental - uma etapa do Planejamento estratégico para Instituições de ensino superior da iniciativa privada: O caso da faculdade de Ciências Sociais Aplicadas de Cascavel - UNIVEL. Dissertação (Mestrado em Engenharia de Produção), Universidade Federal de Santa Catarina, Florianópolis, 2001 
SCHERMERHORN, Johm R. Administração: conceitos fundamentais. Rio de Janeiro: LTC, 2006.

SINDICATO das Entidades Mantenedoras de Estabelecimentos de Ensino Superior no Estado de São Paulo - Semesp. Revista Ensino Superior. Para não perder de vista. Disponível em:

VIANNA; Ilca Oliveira de Almeida. Planejamento Estratégico e Participativo:

elaboração, fatores facilitadores e dificultadores de sua implantação na universidade. IV Colóquio Internacional sobre Gestão Universitária na América do Sul.

Florianópolis, 8 a 10 de dezembro de 2004. Disponível em:

$<$ http://revistaensinosuperior.uol.com.br/imprime.asp?codigo=12806>. Acesso em:

24 set. 2012. 